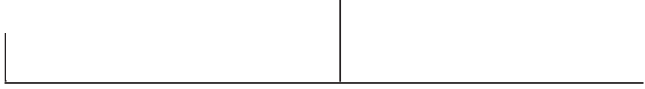

Rev. Latinoam. Psicopat. Fund., São Paulo, 16(4), 702-, dez. 2013

\title{
Literatura, perversão e psicanálise
}

\author{
Norton Cezar Dal Follo da Rosa Jr.*1 \\ Maria Cristina Poli*2
}

A partir de clássicos da literatura, cotejados com a leitura de Jacques Lacan, o artigo aborda as contribuições deste campo para a clínica psicanalítica concernente ao estudo da perversão. Neste momento da pesquisa, propomos a discussão de quatro obras: A filosofia na alcova, escrita pelo Marques de Sade, Em busca do tempo perdido, de Marcel Proust, Lavoura arcaica, de autoria de Raduan Nassar e Finnegans Wake, de James Joyce.

Palavras-chave: Literatura, perversão, psicanálise, Lacan

${ }^{*}$ Associação Psicanalítica de Porto Alegre - APPOA (Porto Alegre, RS, Brasil).

${ }^{* 2}$ Universidade Federal do Rio de Janeiro - UFRJ (Rio de Janeiro, RJ, Brasil). 


\section{Literatura, perversão e psicanálise}

A partir de clássicos da literatura, o presente artigo problematiza as contribuições deste campo para a clínica psicanalítica, em especial, as interrogações concernentes ao estudo da perversão. Neste momento da pesquisa, privilegiamos o debate em torno de quatro obras: A filosofia na alcova, escrita pelo Marquês de Sade (2008/1795), Em busca do tempo perdido, de Marcel Proust (2002/1913), Lavoura arcaica, de autoria de Raduan Nassar (1979) e Finnegans Wake, de James Joyce $(1998 / 1939)$.

Nossa aposta parte do princípio freudiano de que os poetas e escritores têm muito a ensinar aos psicanalistas, sobretudo, naquilo que diz respeito aos impasses da condição humana. Ressalta-se também o valor que Lacan delegava à literatura, sobretudo, porque o seu interesse por ela não estava relacionado a uma lógica de psicanálise aplicada. Então, ao interrogar a nossa prática por meio do diálogo com o texto literário, resgatamos a oportuna observação de Lacan (2003/1965) no texto "Homenagem a Marguerite Duras pelo arrebatamento de Lol V. Stein" de que o analista não deve bancar o psicólogo quando o artista lhe propõe aberturas através de múltiplos caminhos. Assim, a literatura é lida enquanto campo de abertura, de polissemia significante. Isto implica reconhecer que não apenas lemos os textos clássicos como somos lidos por eles. Portanto, ao dialogarmos com Sade, Proust, Nassar e Joyce, consideraremos não a condição biográfica dos autores, mas aquilo que seus textos permitem aceder a diferentes registros da perversão na estrutura do sujeito. 
Assoun (1996), ao abordar a interface entre feminilidade e perversão, também irá tomar como referência as correlações entre psicanálise e literatura. Para avançar em suas interrogações sobre a perversão foi necessário considerar "a necessidade de incluir o texto literário no trabalho da clínica psicanalítica" (p. 6). Diante disso, sua posição não será a de aplicar a psicanálise à literatura, e sim interrogar em que aspecto a psicanálise é captada por ela. Ao propor o diálogo entre estes campos, o autor distinguirá três dimensões balizadoras: em primeiro lugar, considerar o texto literário como um lugar privilegiado para a produção do inconsciente que concerne intimamente à clínica psicanalítica; em segundo, o papel maior desempenhado pela perversão na pós-modernidade literária; e por fim, o fato de que a Mulher, "desafio e aposta de estudo da psicanálise, constitui a cifra própria nesta literatura" (p. 4). Tais observações situam a insuficiência de nossos saberes sobre a sexualidade e, em especial, sobre a perversão.

Consideramos fundamental manter ativa essa dimensão de enigma e desafio, sobretudo no que diz respeito ao campo das perversões, predominantemente marcado por preconceitos, moralismos e saberes categóricos. Como indica Foucault (2011/1975) em Os anormais, a busca por um saber totalizante se encontra nas origens históricas da própria "perversão", quando, a partir do advento do exame médico-legal, dá-se o advento da "categoria de monstro" na literatura. É preciso que a psicanálise mantenha também, e, sobretudo, nesse campo, sua subversão e não confunda o argumento - as encarnações contextuais dos referidos "monstros" - com sua condição de estrutura. Assim, considerando a importância destes aspectos históricos, e relançando a questão no enquadre das relações entre psicanálise e literatura, propomos a seguir uma leitura dos clássicos suprarreferidos acompanhados dos avanços propostos por Lacan a cerca da perversão.

\section{A filosofia na alcova: quando o ideal perverso recusa a filiação}

Lacan (1998/1963), no texto "Kant com Sade" ao discutir o clássico de Sade (2008/1795) A filosofia na alcova, cotejando-o com a Crítica da razão prática de Kant (2011/1788), nos conduz a considerar na obra sadiana uma recusa à filiação inerente a lógica perversa. Isto é possível de ser observado tanto pela recusa da herança do patrimônio simbólico das gerações que antecedem o sujeito, no qual a dívida com os pais e a cadeia geracional não são passíveis de serem reconhecidas, como na recusa da responsabilidade pela transmissão às novas gerações. Neste sentido, se, de um lado, o príncipe dos perversos nos ensina sobre o gozo; de outro, aponta a debilidade da perversão no que diz respeito ao amor, isto é, sobre a dialética da transmissão e do dom. 
Lacan (1997/1959-1960) refere que é preciso ler A filosofia na alcova, acompanhado das fórmulas kantianas da Crítica da razão prática. Seu interesse está em analisar a incidência da ação moral postulada por Kant na Alcova, de Sade, sobretudo, no que diz respeito à Lei fundamental da razão pura prática. Essa lei moral é concebida pelo filósofo como um fato da razão que situa a posição ideal do sujeito em relação à vontade, qual seja: "Age de tal modo que a máxima de tua vontade possa valer sempre como princípio de uma legislação universal" (Kant, 2011/1788, p. 44). Neste enunciado, mais do que uma regra, a noção de vontade visa a um fim, sendo ordenado por um imperativo categórico de pretensões absolutas.

Ao destacar a proximidade cronológica destas duas publicações - Filosofia da alcova e Crítica da razão prática -, Lacan vai acentuar sua análise naquilo que diz respeito à semelhança na lógica que perpassa as teses de Kant e de Sade. Para o psicanalista, a moral sadiana, além de possuir pretensões universais análogas ao imperativo categórico de Kant, irá desvelar o recalcado na experiência moral kantiana, pois, em Sade, o homem terá o direito ao gozo do corpo alheio. Na busca insaciável por um princípio universal, os limites serão transpostos colocando em causa a recusa de qualquer interdição que possa fazer obstáculo ao gozo. O autor sublinha a lógica implícita na busca sadiana: "Tenho direito de gozar de teu corpo, pode dizer-me qualquer um, e exercerei esse direito, sem que nenhum limite me detenha no capricho das extorsões que me dê gosto de nele saciar" (Lacan, 1998/1963, p. 780).

Para Lacan (1998/1963), o texto de Sade irá completar a Crítica da razão prática de Kant justamente porque coloca em cena o objeto que fora recalcado na ética kantiana, a saber, o objeto $a$. Neste aspecto, irá nos dizer que a ética sadiana, ao desnudar o objeto oculto em Kant, é "mais honesta" do que a proposta pelo filósofo. Ressalte-se que a face do objeto em questão é a voz, veículo do supereu. Segundo o psicanalista, "a máxima sadiana é, por se pronunciar pela boca do Outro, mais honesta do que o recurso à voz interior, já que desmascara a fenda, comumente escamoteada do sujeito" (p. 782). Portanto, Sade desvela a máxima kantiana justamente porque não propõe uma disjunção entre lei e gozo, pois a lei em questão é gozar. Diante disso, o psicanalista nos ensina sobre a proximidade entre o ideal de moralidade filosófica em Kant com a perversão sadiana, questão fundamental; sobretudo, em função da tentação relativamente comum de se fazer uma disjunção entre "o campo da moral" e o "universo da perversão". Em vez de considerar o sujeito perverso como um imoral, ou até mesmo um amoral, Lacan indica a moralidade implícita no discurso de um sujeito situado na perversão.

Ao ler esses clássicos como verdadeiros tratados de ética moral, Lacan irá romper com a tentadora dicotomia de tomá-los como opostos - onde a lei moral em Kant estaria a serviço do bem ao outro, enquanto a obscenidade sadiana requereria 
o mal. Portanto, ao transpor os limites, Sade inaugura na literatura a possibilidade de reconhecer aquilo que diz respeito à especificidade do pathos perverso.

\section{Lacan com Proust: o gozo inanimado do perverso}

Ao abordar o ciclo de Albertine, a partir da leitura do clássico de Proust Em busca do tempo perdido, Lacan aprendeu que a lógica da perversão situa-se numa captação inesgotável do desejo do Outro, jogando-o e fixando-o na condição de objeto inanimado. Isto o levará a supor que o perverso se encontra aprisionado em seu próprio fetiche, capturado por uma imagem capaz de reduzir o semelhante à condição de mero instrumento. Ao insistir na tese de o Outro estar na condição de objeto inanimado, o autor reconhece uma especificidade lógica da perversão, pois ao tomar o semelhante como um objeto de gozo, o sujeito irá se situar de forma precária no registro das trocas. Isto por sua vez o levará ao exercício de uma forma de violência que pode se materializar por meio da coisificação do corpo do alheio. A partir da análise da relação do narrador de Proust com Albertine, ele irá se interrogar:

O que é a perversão? Ela não é simplesmente aberração em relação a critérios sociais, anomalia contrária aos bons costumes, se bem que esse registro não esteja ausente (...). Ela é outra coisa na sua estrutura mesma. Não é por nada que se disse de certo número de tendências perversas que são de um desejo que não ousa dizer seu nome. A perversão situa-se, com efeito, no limite do registro do reconhecimento e é isso que a fixa, a estigmatiza como tal. (Lacan, 1996/1953, p. 252)

Como é possível constatar, Lacan indica um traço próprio à perversão no tema do "reconhecimento", pois é o laço do sujeito com o outro que é salientado. Desse modo, através de Proust, ele leu na perversão tanto um gozo pelo inanimado, em que o sujeito se encontra aprisionado, quanto o desejo perverso anônimo e clandestino. Em O objeto da psicanálise, Lacan (1992/1965) vai abordar novamente o clássico de Proust a partir da célebre cena de Montjouvain. Através deste recorte do texto, ele irá tomar o desejo perverso como não sendo capaz de dizer seu nome. A passagem anterior à citação a seguir menciona o fato de o narrador ter ido até Montjouvain. Devido ao calor deitou-se nas moitas e adormeceu; ao acordar, viu através da janela a senhorita Vinteuil buscar às pressas o retrato do pai que se encontrava sobre a lareira, tão logo percebera a chegada da amiga que veio visitá-la. Segue:

Depois, atirou-se sobre um canapé e puxou para junto de si uma mesinha sobre a qual pôs o retrato (...) Vinteuil sentiu que a amiga lhe dava um beijo, soltou um gritinho, fugiu (...) caiu sobre o sofá, coberta pelo corpo da amiga. Mas esta se encontrava de costas para a mesinha onde estava o retrato. A senhorita Vinteuil 
compreendeu que a amiga não o veria se não lhe atraísse a atenção, e lhe disse como se apenas agora estivesse reparado nele: oh este retrato de meu pai que nos olha, não sei quem o pôs aí, já falei mil vezes que não é este o seu lugar. (Proust, 2002/1913, p. 138)

"Um desejo que não ousa dizer o seu nome" é a clausura do anonimato perverso que esbarra com a imago de um pai que lhe cai aos olhos. Neste sentido, se por um lado a posição perversa irá convocar o olhar paterno, por outro, o sujeito parece impedido de reconhecer-se no desejo. Ou ainda, não sustenta a autoria de seu ato: "mas quem colocou este retrato aí já falei mais de mil vezes...". A senhorita Vinteuil, ao enunciar que "não é esse o seu lugar", parece dizer que há nas perversões algo que o sujeito não quer reconhecer. Neste caso, há na perversão uma confusão sobre o reconhecimento do lugar de um pai. Isto irá indicar a sua particularidade em relação à filiação.

Ao destacar essa passagem do texto de Proust, Lacan ressalta aspectos centrais na economia subjetiva do sujeito situado na perversão. Além de situar o Outro na condição de objeto inanimado, o perverso encontra-se condenado a se ofertar incessantemente ao seu gozo. Assim, a leitura de Em busca do tempo perdido mostra-nos a necessidade de conceber a perversão em sua sutileza, por meio de suas manobras delicadas e repertórios ardilosos. Por isso, mais do que pensar a perversão mediante uma visão simplista de pulsões sem amarras, Lacan irá concebê-la a partir da posição do sujeito em relação ao falo. Ao tomá-lo como referência, o psicanalista irá se interessar pela lógica do desejo perverso. Ou ainda, sobre o que esse desejo requer colocar na cena. Neste aspecto, a passagem a seguir nos parece ser esclarecedora:

(...) o fantasma do perverso se apresenta como algo que se poderia chamar uma sequência, quero dizer, como poderíamos chamá-lo em um movie, em um filme cinematográfico, eu entendo uma sequência cortada do desenvolvimento do drama, algo como se vê aparecer sob o nome de rush (...) (Lacan, 2002/1958-1959, p. 467)

$\mathrm{O}$ autor refere uma sequência cortada aparecendo como um rush que produz uma ruptura com o desenvolvimento do drama. Neste sentido, o que essas imagens têm de sedutor diz respeito ao seu aspecto de corte em relação ao tema. Não é deste lugar que a senhorita Vinteuil convoca o pai aos olhos da amiga? O pai na perversão apareceria de forma cortada do drama do sujeito? Reconhecer e recusar, simultaneamente, a existência de um pai seria uma lógica própria a perversão? Então, se o desejo não tem outro objeto senão o significante de seu reconhecimento, qual seria a especificidade do desejo perverso na medida em que o sujeito tende a recusar o reconhecimento?

A perversão procura recusar a todo instante a castração simbólica justamente porque esta será a condição da não existência de um objeto adequado ao gozo. Então, se o perverso supõe deter um saber sobre o gozo, o falo na perversão não será o significante da castração, ou ainda, o significante de uma falta no Outro. Eis o 
engodo perverso: gozar da lei supondo assim capturar o falo. Abre-se aí uma importante via de análise das incidências, tanto clínicas como sociais desse discurso.

\section{Lavoura arcaica: quando um pai goza da "mostração" do desejo}

Quando um pai goza da mostração do desejo ele não irá possibilitar a vetorização da insígnia da falta. Pelo contrário, ele demarca a impossibilidade de o desejo estar orientado na direção de uma mulher, encarnando-o em si mesmo. Propõe-se aí uma sobreposição enganosa do pai imaginário ao pai real. Logo, ao dar visibilidade à "mostração" de seu gozo, o pai subtrai a posição de filiação de seu filho. Um exemplo emblemático da "mostração" do desejo paterno encontra-se no clássico da literatura luso-brasileira Lavoura arcaica, de autoria de Raduan Nassar (1975). Nesse texto, também encontramos contribuições para pensar os efeitos do discurso paterno no desencadeamento de atos perversos através da recusa à filiação. Ao abordar a violência sobre o viés da relação incestuosa, onde a entrega dos corpos à família situa-se na manutenção eterna dos filhos na própria casa, Nassar demonstrou o quanto o enunciado paterno pode autorizar agenciamentos perversos. Vejamos o diálogo de André, o protagonista da trama, com a sua irmã: "foi um milagre descobrirmos acima de tudo que nos bastamos dentro dos limites de nossa própria casa, confirmando a palavra do pai de que a felicidade só pode ser encontrada no seio da família" (p. 120).

A partir da fala de André, podemos supor que os ditos do pai, além de capturar os corpos de seus filhos, em face do imperativo de laborar a terra, autoriza a relação incestuosa entre os irmãos. Portanto, a "mostração" do desejo paterno é materializada na territorialização do gozo no seio familiar, pois se o sujeito se basta no lastro da família ele corre o risco de transformá-la num templo de gozo. Sendo assim, o excesso de familiaridade pode ser enlouquecedor e jogar o sujeito no limite da paixão ensandecida. Esta, não permite reflexão, requer apenas a resposta mimética.

Querida Ana, te chamo ainda à simplicidade, te incito agora a responder só por reflexo e não por reflexão, te exorto a reconhecer comigo o fio atávico dessa paixão: se o pai, se o pai no seu gesto austero, quis fazer da casa um templo, a mãe, transbordando em seu afeto, só conseguiu fazer dela uma casa de perdição. (p. 136)

A "mostração" do desejo paterno remete à hipótese de o pai estar situado numa dimensão de precária legitimidade. Neste caso, a posição perversa deste em relação ao filho poderá implicar o reconhecimento do pai no lugar de um gozador. Como situa Poli (2005), Lavoura arcaica evidencia um funcionamento automático e repetitivo da instituição familiar, que faz de seus membros elos em uma 
engrenagem desprovida de sujeito. É preciso considerar, portanto, as incidências subjetivas de quando o pai imaginário irá se suplantar a instância simbólica da insígnia paterna. Neste caso, a "mostração" do desejo paterno irá confrontar o filho com um excesso de gozo. Assim, ao se instituir no lugar de guardiã do imperativo superegoico, a família faz-se agente de um discurso regido pela recusa à castração. O pai dessa lavoura ao invés de se submeter à lei se confundiu com ela, fazendo desta, um imperativo do gozo.

A família que Lavoura arcaica nos apresenta é a instituição guardiã do imperativo superegoico, a detentora da técnica de reintegração do produto a sua matriz. Trata-se, exemplarmente, de um discurso dirigido pela recusa à castração. (p. 240)

Conforme destaca a autora, ao problematizar os impasses do trabalho de subjetivação da adolescência de André, esse filho tão diferente dos outros, haja vista sua insubmissão ao rígido código de conduta familiar, entre os seis irmãos, ele é o único a desafiar o pai em sua autoridade. Apesar da aparente oposição, André faz uma espécie de espelhamento com o gozo paterno, identificando-se com a lei do imperativo ao gozo, pois ele atribui ao pai o legítimo detentor de tal discurso na estrutura familiar. Isto nos faz reconhecer os danos de quando um pai não vetoriza o desejo ao filho, pois ele encarna o falo como imagem de potência, impedindo um circuito de trocas.

Lavoura arcaica nos ensina que a "mostração" do desejo paterno não irá proteger o filho de um excesso de gozo, pelo contrário, pois quando o pai não situa alhures o objeto causa de desejo, o desejo em questão não poderá se inscrever na condição neurótica do impossível ou insatisfeito. Neste caso, mais do que um pai simbolicamente frágil, trata-se de um gozador. Será da incitação ao ato, movido pelo superego obsceno, que a angústia do filho irá gozar. Logo, faz-se necessário também considerar a importância de um pai vetorizar o desejo em sua vertente constituinte. A leitura de Lacan, de Joyce, será decisiva nesta questão.

\section{Lacan com Joyce: a pai-versão enquanto amor eterno}

No Seminário RSI, na lição de 21 de janeiro de 1975, Lacan afirma que o pai real é um homem cujo desejo é causado por uma mulher: a mãe de seus filhos. Nesta ocasião, enuncia que um pai só tem direito ao respeito, senão ao amor, se ambos forem pèreversament orientados, isto é, se ele fizer de uma mulher o objeto pequeno $a$, causa de seu desejo. Com isto, o pai real não será somente o portador do trunfo, o demarcador da diferença geracional e o agente da castração. Ele 
possibilitará a vetorização do desejo enquanto insígnia da falta, salvando o filho do gozo diante dos incestuosos tentáculos maternos. Este pai, ao instaurar um limite entre prazer e gozo, viabiliza o desejo.

Portanto, a homofonia entre perversion e père-version, perversão e versão do pai, irá situar a possibilidade de um desejo estar orientado na direção de uma mulher, condição do héteros para ambos os sexos, a qual possa ocupar o lugar de objeto $a$. Então, ao reconhecer que a palavra francesa pèrversion (perversão) comporta os significantes père (pai), vers (em direção a) e version (versão), Lacan compreendeu que a perversão será tanto uma espécie de versão do pai quanto busca deste. Este será o amor paterno pèreversament orientado. Neste aspecto, cabe uma ressalva. Não se trata de um pai que transmite ao filho a encarnação do desejo em alguma instância de materialização objetal. Para ser mais preciso: não se trata de um pai que goza a partir da "mostração" do desejo, como, por exemplo, o pai de Lavoura arcaica. Ao fazê-lo, ele transmite o engodo da captura do objeto-causa do desejo, como se pudesse ser seu ao invés de tomá-lo como desejo do Outro. Neste caso, o pai que goza da "mostração" do desejo, tende a fetichizá-lo. Em vez de respeito, ele demanda ser imitado pelo filho, pois como aponta Chemama (2007), o simples fato de indicar seu desejo, com bastante nitidez para que o filho o perceba, teria aí algo de uma conotação perversa.

Ao fazer da letra dejeto, Joyce inaugura uma escrita onde o sujeito teria inventado uma forma de se sustentar nas falhas da estrutura do Nome-do-Pai. Lacan passa a analisar essa obra, partindo do pressuposto de que o Nome-do-Pai estaria foracluído do texto joyciano. Logo, a sua escrita teria por função corrigir essa falha. Desse modo, ao cunhar o termo "Sinthome", diferenciando-o do conceito clássico de sintoma clínico, o psicanalista reconheceu em Joyce a possibilidade de resolver a insuficiência de um pai, sem enlouquecer. Portanto, Joyce irá nos auxiliar a conceber a existência de um quarto registro que terá a função de enodar $\mathrm{R}, \mathrm{S}$ e I. Isto ajudará Lacan a não conceber a perversão simplesmente a partir da sobreposição do registro imaginário em relação aos demais, como é possível constatar em seminários anteriores. Neste momento, a pèrversion será definitivamente uma versão possível de se dirigir ao pai. Então, ela concerne à condição de sujeito, independente de estrutura psíquica. Isto levará Lacan a afirmar que não existe relação sexual, pois o sinthoma impossibilita a ilusão de uma plena harmonia entre os sexos, ou seja, de que a partir de dois seja possível fazer Um. Em contrapartida, será a partir dele que poderá haver um laço entre os registros R, S e I. Sendo assim, torna-se condição para haver laço social.

Lacan passa a problematizar o lugar reservado ao pai na escrita de Joyce, levando-nos a supor uma possível relação sadomasoquista entre pai e filho, pois o gozo que ligava Joyce ao pai fez dele uma espécie de redentor diante da missão de fazer um nome. Ao analisar a função da escrita de Joyce, apesar de supor uma 
psicose, o psicanalista reconhece nela uma forma de suplência à carência da função paterna. Assim, Joyce teria inventado um enodamento do nó borromeano: o sinthoma.

Não há nisso alguma coisa como uma compensação dessa demissão paterna, dessa Verwerfung de fato, no fato de Joyce ter se sentido imperiosamente chamado? Essa é a palavra que resulta de um monte de coisas que ele escreveu. É a mola própria pela qual o nome próprio é, nele, alguma coisa estranha. (Lacan, 19751976/2007, p. 86)

O pai de Joyce não lhe transmitiu o Nome-do-Pai. Por outro lado, contudo, por meio de sua escrita ele teria feito de seu nome uma compensação à foraclusão. Seu desejo de ocupar os universitários por séculos, inclusive até a extinção da universidade, seria a compensação daquilo que o pai jamais fora para ele. Assim, Joyce sustenta o pai, fazendo sua família subsistir ao torná-la ilustre. Neste sentido, a condição de "redentor" situa a forma de gozo que faria referência ao pai. Por isso, para Lacan, também a escrita de Joyce trouxe contribuições relevantes para pensarmos a perversão. Isto o levou a reconhecer que este autor lhe permitiu compreender algo novo.

Toda a sexualidade humana é perversa, se acompanharmos bem o que diz Freud. Ele nunca conseguiu conceber a tal sexualidade sem ser perversa, e é justamente neste aspecto que interrogo a fecundidade da psicanálise (...) penso que graças a Joyce, tocamos alguma coisa que eu jamais havia considerado. (Lacan, 2007/1975-1976, p. 149)

No transcorrer deste artigo extraímos alguns elementos destes clássicos para que pudéssemos, a partir de nossa leitura de Lacan, reconhecer as contribuições da literatura para a clínica psicanalítica com a perversão. Nossos recortes decantam os limites de um ato de leitura, pois os textos em questão transcendem as nossas possibilidades de interpretação. Logo, em relação ao humano na perversão sempre haverá mais para se dizer.

\section{Referências}

Assoun. P.-L. (1996). Le pervers et la femme. Collection Psychanalyse dirigée par Michel Gardaz. Paris: Economica.

Chemama, R. (2007). La jouissance, enjeux et paradoxes (Collection húmus, subjectivité et lien social, dirigée par Jean-Pierre Lebrun). Paris: Érès.

Foucault, M. (2011). Os anormais: curso no Collège de France. São Paulo: Martins Fontes. (Trabalho original publicado em 1974-1975).

Joyce, J. (1999). Finnegans Wake/Finnicius Revém. Versão Donaldo Schüler. Porto Alegre: Ateliê Editorial. (Trabalho original publicado em 1939). 
Kant, I. (2011). Crítica da razão prática. São Paulo: Martin Claret. (Trabalho original publicado em 1788).

Lacan, J. (1974-1975). O seminário. Livro 22. RSI. Inédito.

Lacan, J. (1992). O seminário. Livro 13. El objeto del psicoanalisis. Publicação interna da Escola Freudiana de Buenos Aires. (Trabalho original publicado em 1965-1966).

Lacan, J. (1996). O seminário. Livro 1. Os escritos técnicos de Freud. Rio de Janeiro: Jorge Zahar. (Trabalho original publicado em 1953).

Lacan, J. (1997). O seminário. Livro 7. A ética da psicanálise. Rio de Janeiro: Jorge Zahar. (Trabalho original publicado em 1959-1960).

Lacan, J. (1998). Kant com Sade. In Escritos. Rio de Janeiro: Jorge Zahar. (Trabalho original publicado em 1963).

Lacan, J. (2002). O seminário. Livro 6. O desejo e sua interpretação. Publicação não comercial. Circulação interna da Associação Psicanalítica de Porto Alegre. (Trabalho original publicado em 1958-1959).

Lacan, J. (2003). Homenagem a Marguerite Duras pelo arrebatamento de Lol V. Stein. In Outros Escritos. Rio de Janeiro: Jorge Zahar. (Trabalho original publicado em 1965).

Lacan, J. (2007). O seminário. Livro 23. O sinthoma. Rio de Janeiro: Jorge Zahar. (Trabalho original publicado em 1975-1976).

Nassar, R. (1979). Lavoura arcaica. Rio de Janeiro: Record/Altaya.

Poli, M. C. (2005). Clínica da exclusão: a construção do fantasma e o sujeito adolescente. São Paulo: Casa do Psicólogo.

Proust, M. (2002). Em busca do tempo perdido. Rio de Janeiro: Ediouro. (Trabalho original publicado em 1913).

Sade, M. (2008). A filosofia na alcova, ou, os preceptores imorais. São Paulo: Iluminuras. (Trabalho original publicado em 1795).

\section{Resumos}

(Literature, perversion and psychoanalysis)

Based on literary classics viewed through concepts of Jacques Lacan, in this paper we discuss contributions from the field of literature to psychoanalytic clinical work rlated to the study of perversion. At this point in the research we are discussing four books: "Philosophy in the Bedroom," by Marques de Sade, "In Search of Lost Time," by Marcel Proust, "To the Left of the Father," by Raduan Nassar, and "Finnegans Wake," by James Joyce.

Key words: Literature, perversion, psychoanalysis, Lacan 
(Littérature, perversion et psychanalyse)

À partir de la comparaison de classiques de la littérature avec la lecture de Jacques Lacan, l'article aborde les contributions de ce domaine pour la clinique psychanalytique concernant l'étude de la perversion. À ce niveau de la recherche, nous proposons la discussion de quatre cuvres: "La philosophie dans le boudoir" du Marquis de Sade, "A la recherche du temps perdu" de Marcel Proust, "Lavoura arcaica" de Raduan Nassar et "Finnegans Wake" de James Joyce.

Mots clés: Littérature, perversion, psychanalyse, Lacan

\section{(Literatura, perversión y psicoanálisis)}

A partir de clásicos de la literatura, cotejados con la lectura de Jacques Lacan, el artículo aborda las contribuciones de este campo para la clínica psicoanalítica concerniente al estudio de la perversión. En este momento de la pesquisa, proponemos la discusión de cuatro obras: "La filosofía en la alcoba", escrita por el Marqués de Sade, "En busca del tiempo perdido", de Marcel Proust, "Agricultura arcaica", de autoría de Raduan Nassar y "Finnegans Wake”, de James Joyce.

Palabras clave: Literatura, perversión, psicoanálisis, Lacan

\section{(Literatur, Perversion und Psychoanalyse)}

Ausgehend von Literaturklassikern, die einer Lektüre von Jacques Lacan gegenübergestellt werden, bespricht dieser Artikel die Beiträge aus diesem Bereich zur psychoanalytischen Klinik bezüglich der Untersuchung der Perversion. Zu diesem Zeitpunkt der Untersuchung schlagen wir hier die Diskussion von vier Werken vor: „Die Philosophie im Boudoir", von Marquis de Sade; „Auf der Suche nach der verlorenen Zeit" von Marcel Proust; „,Das Brot des Patriarchen“, vom Raduan Nassar; und ,Finnegans Wake“, von James Joyce.

Schlüsselwörter: Literatur, Perversion, Psychoanalyse, Lacan

Citação/Citation: Rosa Jr., N. C. D. F. da; Poli, M. C. (2013, dezembro). Literatura, perversão e psicanálise. Revista Latinoamericana de Psicopatologia Fundamental, 16(4), 702-714.

Editor do artigo/Editor: Fabiano Massarro Salvador

Recebido/Received: 10.8.2013/ 8.10.2013 Aceito/Accepted: 26.10.2013/10.26.2013 
Copyright: (C) 2009 Associação Universitária de Pesquisa em Psicopatologia Fundamental/ University Association for Research in Fundamental Psychopathology. Este é um artigo de livre acesso, que permite uso irrestrito, distribuição e reprodução em qualquer meio, desde que o autor e a fonte sejam citados / This is an open-access article, which permits unrestricted use, distribution, and reproduction in any medium, provided the original author and source are credited.

Financiamento/Funding: Os autores declaram não terem sido financiados ou apoiados / The authors have no support or funding to report.

Conflito de interesses/Conflict of interest: Os autores declaram que não há conflito de interesses / The authors declare that has no conflict of interest.

\section{Norton Cezar Dal Follo da Rosa JR}

Psicanalista; Analista Membro da Associação Psicanalítica de Porto Alegre - APPOA (Porto Alegre, RS, Br); Doutorando no PPG em Psicologia Social e Institucional na Universidade Federal do Rio Grande do Sul - UFRGS (Porto Alegre, RS, Br); bolsista da Coordenação de Aperfeiçoamento de Pessoal de Nível Superior - Capes (Brasília, DF, Br).

Rua Pinheiro Machado, 451/702 - Morro do Espelho

93030-230 São Leopoldo, RS, Br

e-mail: nortonjr@brturbo.com.br.

\section{Maria Cristina Poli}

Professora do PPG da Universidade Federal do Rio de Janeiro - UFRJ (Rio de Janeiro, RJ, Br) e do Mestrado Profissional Psicanálise, Saúde e Sociedade da Universidade Veiga de Almeida (Rio de Janeiro, RJ, Br); Analista Membro da Associação Psicanalítica de Porto Alegre - APPOA (Porto Alegre, RS, Br); Pesquisadora do Conselho Nacional de Desenvolvimento Científico e Tecnológico - CNPq (Brasília, DF, Br).

Universidade Federal do Rio de Janeiro

Instituto de Psicologia

Rua Pasteur, 250 - Praia Vermelha

22290-240 Rio de Janeiro, RJ, Br

e-mail: mcrispoli@terra.com.br. 